\title{
Lessons from International Students' Reaction to the 2011 Great East Japan Earthquake: The Case of the School of Engineering at Tohoku University
}

\author{
Oscar A. Gómez* \\ Graduate School of Global Studies, Doshisha University, Kyoto 602-0898, Japan
}

\begin{abstract}
The objective of this study is to document the reaction of international students to the 11 March 2011 emergency in order to inform and improve disaster management strategies, both public and institutional. The study is based mainly on a questionnaire survey carried out in August 2011 and follow-up interviews with students and other stakeholders. It describes the background of Tohoku University's School of Engineering and covers six different stages in the evolution of the emergency: (1) immediate response; (2) taking shelter in Sendai; (3) life in the city during the aftermath; (4) sheltering outside Sendai; (5) coming back; plus (6) an overview of the experience. Major findings include: the process of evacuation and safety confirmation was successful, yet the subsequent phases (2 and 3 ) went on mostly unmanaged; students relied mostly on secondary sources of information to make decisions, mainly family and friends of the same nationality, most of whom probably were not better informed than the students themselves. Based on the findings, suggestions for future disaster planning are advanced, as well as a discussion on the challenges of information provision during crisis.
\end{abstract}

Keywords collective behavior, disaster management, emergency response, Great East Japan Earthquake, information collection, international students

\section{Introduction and Background of the Study}

The Great East Japan Earthquake in March 2011 triggered manifold situations that tested the preparedness and resilience of society as a whole. The advanced stage of Japanese globalization in terms of people, goods, capital, and information, adds several layers of complexity to emergency management, resulting in several emerging challenges. A specially demanding new task was communicating the situation and catering to international students. Attention to foreigners in general received limited though passionate attention during the first part of the emergency, especially in the mass media, in institutions directly linked to foreigners' life in Japan, and among

\footnotetext{
* E-mail: iq.oscargomez@gmail.com
}

persons with foreign background. For instance, an editorial in the Asahi Shinbun decried the apparent stampede of foreigners out of the country, concluding that the reconstruction process was a task of none but Japanese (Asahi Shinbun 2011). In other national and international media, as well as in Internet social networks, the discussion followed suit. Nonetheless, there has been little to no academic input to this discussion and so the present survey is a contribution in that respect.

The main goal of this study is to document the reaction of international students to the emergency in order to inform and hopefully improve disaster management strategies, both public and institutional. It presents the case of the Engineering School of Tohoku University, located in Sendai. The city is the closest large urban area to the epicenter of the earthquake, and Tohoku University is the biggest in the city, one of the top 10 educational institutions of the country, and ranks among top 100 of the world. Given its international stature, Tohoku University hosts numerous international students and researchers. In fact, 28.1 percent of the 10,271 foreigners registered in Sendai have international student visas, the largest share by occupation (Sendai City Government 2013), about 60 percent of them are enrolled in Tohoku University. Among the 10 schools that comprise the university, the Engineering School hosts the largest number of international students. At the time of the disaster, 485 persons, including exchange and short-term students, were studying at the Engineering School. A total of 85 percent of the international students come from Asian countries with the majority being Chinese (40\%) and Korean (20\%). About 45 percent of all international students were enrolled in doctoral courses, 32 percent studied in masters programs, 17 percent were undergraduates, and 5 percent were research students who usually were in the process of joining one of the graduate programs. A focus on the university and the engineering school offers a valuable entry point to understand the situation of the international student population, which in the Kanto area reaches more than 60,000 persons.

The School of Engineering and its related graduate schools are located in two university campuses, Aobayama and 
Katahira; most of the international students arriving at Tohoku University stay or live close to the dormitories at Sanjo (Figure 1). After the earthquake, all buildings were evacuated and no fatalities were reported. At the school of Engineering in Aobayama from around 4:30 p.m. those able to go back home were free to do so. The university is not a designated shelter, yet after the tremors, the safety of at least two buildings, one in each campus, was determined and preparations for in-house sheltering were undertaken, with around 300 persons staying at the Aobayama central hall shelter. Among these preparations, a paper-based record of the people there was compiled and whiteboards for information sharing were also set up.

In terms of physical damage, three buildings of the faculty were deemed unsafe for further usage, and another handful received a yellow grade of danger - some areas are affected, but persons could enter those buildings. Located close to Sendai city central station, Katahira campus was the fastest to recover electricity and water supply from the Engineeringrelated areas. At least one of the pumps used to provide water to Aobayama campus was damaged by the earthquake and it took more than a week to repair; water and electricity supply were totally recovered by 1 April, although city gas supply recovery took a little longer. The Graduate School of Environmental Studies had installed a grid of solar cells that were used by people in need of electricity, especially cellphones, although the quality of the signal for the latter was deficient.

After assessing the situation, the university decided to suspend classes and graduation ceremonies, as well as to postpone the beginning of the new academic year on 1 April. The decision was made public on the university homepage on 16 March. Because March is spring break at the university, the time of year when graduation ceremonies are held and students are free to take some time off, students begin to leave campus as early as the middle of February in some cases. Ordinarily classes restart in the first week of April, but because of the earthquake, they did not begin until the second week of May. A time line of major events is included in Table 1.

\section{Literature review}

There is very little literature specific to the reaction of international students to large-scale disasters. Schuh and Santos Laanan (2006) describe the case of students in general and

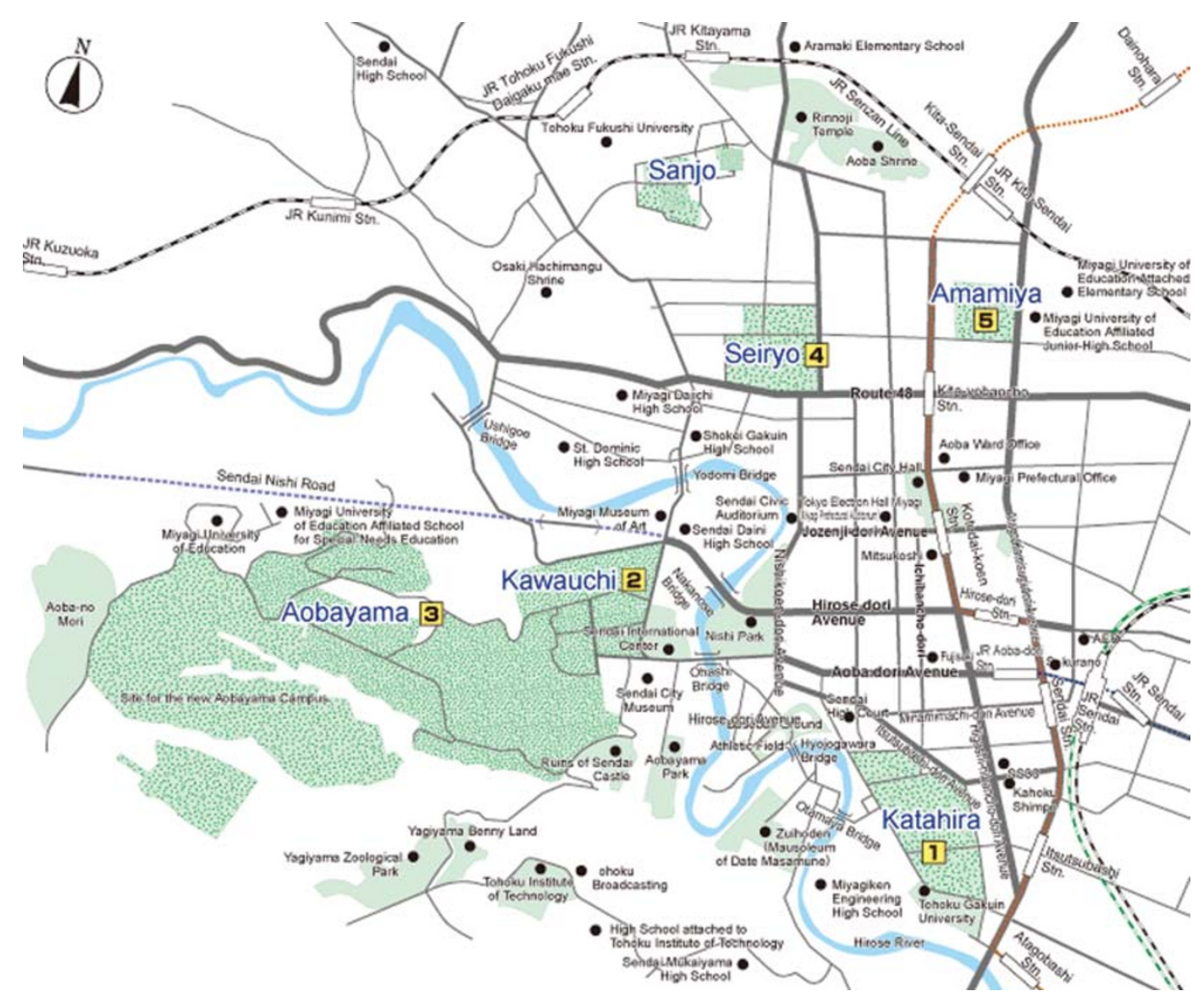

Figure 1. Map of Tohoku University facilities in Sendai city

Source: Tohoku University home page (https://www.tohoku.ac.jp/english/profile/campus/01/access/). 
Table 1. Timeline of major actions by actor

\begin{tabular}{|c|c|c|c|}
\hline Day & University & School of Engineering & International Students \\
\hline $\begin{array}{l}\text { March } 11 \\
\text { (Friday) }\end{array}$ & $\begin{array}{l}\text { - Establishing central crisis response } \\
\text { team }\end{array}$ & $\begin{array}{ll}\text { - } & \text { Building evacuation } \\
\text { - } & \text { First paper-based safety confirmation } \\
\text { - } & \text { Disbanding (circa 4:30) } \\
\text { - } & \text { Temporary shelters established }\end{array}$ & $\begin{array}{l}\text { - Start of sheltering decisions } \\
\text { - } \quad \text { Start of safety confirmation with } \\
\text { families and acquaintances }\end{array}$ \\
\hline March 13 & & & $\begin{array}{l}\text { - First foreign government sponsored } \\
\text { evacuation leaving Sendai }\end{array}$ \\
\hline March 14 & & $\begin{array}{l}\text { - Meetings within schools and general } \\
\text { meetings }\end{array}$ & - Peak of students leaving the city \\
\hline March 15 & - First message from the president & & $\begin{array}{l}\text { - } 100 \% \text { of students report contact with } \\
\text { families }\end{array}$ \\
\hline March 16 & $\begin{array}{l}\text { Decision to close the university } \\
\text { published in the university homepage }\end{array}$ & & \\
\hline March 17 & $\begin{array}{l}\text { - Announcement about the official } \\
\text { safety confirmation system }\end{array}$ & & - Peak of students leaving the country \\
\hline March 18 & $\begin{array}{l}\text { - Results of first on-campus radiation } \\
\text { levels measurement }\end{array}$ & & $\begin{array}{l}\text { - } 100 \% \text { of students report contact with } \\
\text { the university }\end{array}$ \\
\hline Start of April & & $\begin{array}{l}\text { - Total water and electricity recovery } \\
\text { - Full safety confirmation }\end{array}$ & \\
\hline May 9 & Official re-start of classes & & \\
\hline
\end{tabular}

suggest a hypothetical scenario informed by the aftermath of Katrina in the United States. Cavanaugh (2006) advances a general crisis management plan for universities; both papers are without relevant references and based on anecdotal evidence. The volume edited by Suzuki (1996), who documents the experience during the Kobe Earthquake in 1995 through personal accounts, case studies, analysis of the news, and a quantitative survey, is the only example at hand. Some general issues of concern during 2011 also emerged in 1995 , namely: how to confirm safety, how much can/should university persons in charge do, the problem of living in a city with a disrupted lifeline, and whether foreign students should leave the city/country or not. Nonetheless, the two disasters are different in ways that make comparison difficult. In terms of damage, the 1995 earthquake directly hit Kobe City, resulting in heavy infrastructure destruction and the outbreak of fires that caused 12 casualties among international students. In contrast, in the largest city close to the epicenter, Sendai, physical damage because of the 11 March 2011 earthquake was limited and no international student victim was reported. The advance in information and communication technologies during the last 17 years has been remarkable, so while in the past the safety confirmation was done mainly face to face or through paper-based lists in Kobe, in 2011 there was a wider range of options available. Perhaps more significantly, the emergency in Fukushima No. 1 nuclear power plant was a crucial factor conditioning behavior after the earthquake and the tsunami struck. In other words, the possibility of a comparative analysis is limited.

A broader view on the literature encounters the question of whether international students are actually a vulnerable population in need of special treatment. Globally recognized guidelines for disaster response, such as the IASC (2006) or the Sphere Project (2011), include as vulnerable populations internally displaced persons, women, children and adolescents, older persons, persons with disabilities, persons living with HIV/AIDS, single parent households, ethnic and religious minority groups, and indigenous peoples. Some international students may belong to some of them but not all of them as a group. Academic compilations, such as the four tomes prepared by the Hyogo Earthquake Memorial 21st Century Research Institute (2011) or Wisner, Gaillard, and Kelman' handbook (2012), do not include them. Not even Kuban and MacKenzie-Carey's effort (2001) to develop a methodology to determine specific vulnerable populations resulted in international students inclusion in their long list of potential candidates.

Nonetheless, there are at least two major arguments that warrant attention over international students' condition of special vulnerability: one is their commonality with emerging vulnerable groups and the other is the inadequacy of the approach existing in Japan.

In terms of international students' commonality with emerging vulnerable groups, some insights can be drawn from the existing literature about the closest recognized categories: minorities or tourists. Drabek (1999) found that ethnic minorities tend not to trust official disaster warnings. Particularly in the case of Katrina, there is evidence showing that a combination of poverty and perceptions of racism and inequities were among the reasons for African Americans not to evacuate (Elder et al. 2007). Bankoff (2012) suggests that minorities could be blamed for the disaster, which is in fact 
not new, since after the Kanto Earthquake in 1923 rumors of foreigners vandalizing the city triggered the killing of thousands of Koreans by vigilante groups.

Tourists in popular destinations hit by a mega-disaster, such as those affected by the Indian Ocean tsunami, do become vulnerable (Steckley and Doberstein 2011) and can even overwhelm the local system (Deebaj, Castrén, and Öhlén 2011). Some 20,000 Swedes, 10,000 Britons, and 4,000 Finns were in the disaster area, with all the logistic problems such large numbers generate. It has been suggested that foreigners may be more prone to post-traumatic stress disorder (PTSD) (Yonekura 2012), but there is no solid evidence in this respect. At least in connection to suicidal behavior there are no definitive conclusions that can be drawn (Kõlves, Kõlves, and De Leo 2013), specially because suicidal behavior may follow complex, non-linear patterns (Matsubayashi, Sawada, and Ueda 2013).

International students may or may not share some of these conditions of vulnerability. They are a minority but are neither homogeneous in terms of ethnicity nor historically pressured by society. They may have no deep roots in the city, but they are not as transient as tourists. These similarities merit further investigation.

In the same way as it seems inaccurate to treat international students as minorities or tourists, the category "foreigners," widely accepted in Japan (Naito 2011; Sendai City Government 2013), also seems flawed. The category "foreigners" puts permanent residents and tourists, housewives and international students into the same box. Researchers who have tried to study foreigners as a single population in the context of disaster management attest to their heterogeneity (Henry, Kawasaki, and Meguro 2012; Omura 2012; Yonekura 2012).

The reasons for the inclusion of foreigners as a vulnerable population, namely language capacity and cultural/religious practices (Kimura 2012), do not hold water. The differences in language skills among foreigners are too evident to require further comment. No rigorous research is available about how the cultural differences of foreigners in Japan affect disaster response, and related literature usually relies primarily on anecdotal evidence (Kimura 2012; Naito 2011). Studies elsewhere have pointed out that the cultural argument may not be significant even for tourists. Seabra et al. (2013) show that the risk perception of tourists varies widely, and Reisinger and Crotts (2010) present evidence revealing that cultural differences among tourists from different countries are not as significant as differences among tourists from the same country. Reaction to risk seems to depend much on contextual characteristics. Drabek (1999) points out divergence in the resulting behaviors depending on whether tourists are starting or ending their trips, and whether they are staying at a hotel or with relatives.

Nonetheless, it has been recognized that "foreignness" can be a source of special vulnerability (Tompkins, Hurlston, and Poortinga 2009). Lack of language skills can become a source of vulnerability, no matter if the person is a foreigner or not.
U.S. legislation on nondiscrimination in disaster assistance was modified after Katrina, adding English proficiency (or lack thereof) to such traits as race, color, religion, nationality,

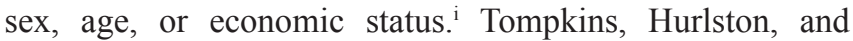
Poortinga (2009) show how in the Cayman Islands not only migrants but even returning residents who spend some significant time living abroad adopt "foreign" views about location, valuing the benefits of coastal sites above their risks. Their forgetfulness thus results in more exposition to hurricanes and tropical storms, which can be associated to a cultural change.

The crux of the matter is the need to reconcile these (and probably other) legitimate sources of vulnerability with the practical need to identify target groups for the design of policies and protocols of action. By documenting the reaction of international students, the present work suggests alternative populations that better satisfy these two needs in order to better tailor disaster risk reduction activities.

\section{Methodology}

To investigate the reaction of international students from the School of Engineering at Tohoku University, a questionnaire survey was developed. The survey was designed to collect basic information about students' behavior through each stage of the emergency, as well as personal characteristics of relevance for the analysis. The stages -1 to 6 in Table $2-$ were defined through discussions with professors of the school and personal observation during the disaster; it also was pretested with 10 students from other schools. Themes of greater interest were the safety confirmation process, sheltering behavior, needs satisfaction, and inputs for individual decisionmaking.

The questionnaire was distributed through the school mailing list for international students on 4 August 2011, and the deadline for submission of responses was 21 August. Access to the official mailing list implied that no sampling was necessary, yet this only covered active, regular and prospective students, so the survey did not reach exchange students, who visit the university for less than one year. Therefore, the actual population decreased from 485 to 396 persons, out of which 97 replied (return rate of 24.5\%). The language of the survey was English, which was consider valid since a high level of proficiency is required to enter the university; still, respondents were free to answer in Japanese.

Concerning the respondents, 20 percent of them were women and 20 percent of the respondents live with their husband or wife, but no couple answered the questionnaire. Eight percent of the respondents have children. The language proficiency is as follows: no Japanese 24 percent, intermediate 32 percent, and advanced 44 percent. Funding for a third of the sample comes from the Ministry of Education (MEXT); other scholarships support 37 percent of the international students, while 28 percent receive no scholarship funds. The average stay in Japan of surveyed students is 25 months. 
Table 2. Queries included in the survey questionnaire

Survey questions

1. Immediate Response

1.1. Where were you when the earthquake occurred?

1.2. How did you confirm your personal safety to others? University, Family, Others.

1.3. Did you receive official safety confirmation requests? From whom? By what means? In what language?

1.4. What do you think was the best (more efficient) means for confirming your personal safety?

2. Taking Shelter in Sendai

2.1. Did you sleep somewhere other than your own place? If no, what were your reasons for not taking shelter?

2.2. Did you stay in more than one shelter? If yes, how many?

2.3. Where?

2.4. If you changed shelters within Sendai, please tell us your reasons.

2.5. Did you experience any difficulties in the shelter(s)? What difficulties?

2.6. What did you do after taking shelter?

2.7. What were the most important reasons for your decision?

2.8. What were your main sources of information that conditioned your decision?

2.9. Were you contacted by your embassy?

3. Life in Sendai During the Aftermath

3.1. What were the main factors preventing you from going back to your apartment/room in Sendai?

3.2. Did you have to queue for food, water, or gas?

3.3. Where did you get your daily food and water?

3.4. Did you have problems in moving around Sendai?

3.5. When did you come to know about the problem in Fukushima?

3.6. How did it affect you?

4. Sheltering Outside Sendai

4.1. When did you move out of Sendai?

4.2. What mean (s) did you use?

4.3. Where did you stay?

4.4. Did you experience shortages of supplies or utilities outages? If yes, which?

4.5. When did you come to know about the problem in Fukushima? How did it affect you?

4.6. Did you leave the country?

4.7. What were the most important reasons for this decision?

4.8. Did your sources of information for making decisions change?

4.9. When applicable, did you have to leave Japan without a re-entry permit?

5. Back to Sendai

5.1. When did you come back to Sendai?

5.2. Did you change your date of return at least once?

5.3. What were the main factors in setting the date?

6. In Hindsight,

6.1. What do you think about the reaction of: the University, Yourself

6.2. What do you think would be the best possible reaction in a future emergency?

6.3. Did you receive any training in the past about how to react when an earthquake occurs?

6.4. Could you apply that knowledge this time?

7. Your Data

The collected data were analyzed through simple contingency tables, exploring the association between respondents' traits and behavior during the emergency, as well as the influence between the stages in the evolution of the emergency specified in the questionnaire. Significance in the difference between the proportions in contingency tables of categorical variables for groups such as those covered in this research are more frequently assessed using Pearson's chi-squared test; however, this test requires large samples in order to give valid results. Since, for instance, only 24 percent of respondents know no Japanese, a contingency table exploring the association of language proficiency with the type of shelter selected for the first night - university, designated shelter, home, or other-would not satisfy the condition for chisquare to be valid. In those cases, it is necessary to use Fisher's exact test, which was calculated using the software R (Agresti and Finlay 2009).

Finally, the findings are complemented with other kinds of qualitative evidence available for the research, namely insights from semi-structured interviews with international students and researchers $(N=16,5$ from the Engineering School), informal discussions at the university, direct observation, and the inputs from projects such as the study carried out by Toushinroku, Takakura, and Kimura (2012), which includes oral accounts of individual student disaster experiences. The interviewees were selected through snowball sampling, which is a common approach when dealing with small populations that are difficult to locate (Weiss 1994). In our case, the intention was to interview students from other campuses and different backgrounds in order to explore the possibilities of extrapolating the results for all the students of the university. While the evidence is not enough for the latter aim, these data are of use in clarifying and adding nuance to the findings of the survey.

\section{Survey Results}

Through this section, a summary of the replies to the questionnaire for each stage of the emergency included in Table 2 is presented. Clarification drawn from the follow-up interviews is included when appropriate.

\subsection{Immediate Response}

The stage of immediate response included questions regarding the place where students experienced the earthquake and details of the safety confirmation process. International students were also asked about the best way to confirm safety.

\subsubsection{Contact to University}

From the 78.4 percent of students who were in Sendai on 11 March, 2:46 p.m., 65.8 percent were at the university, 10.5 percent were at home, 5.3 percent were somewhere else, and the other 18.45 percent did not offer details. We inquired when and how they confirmed their personal safety with the university and their families. The university was generally informed in person (59\%), followed by e-mail (26\%) and cellphone (14\%). The answer "personally" includes paperbased notification at the temporary shelters on each campus 
or by directly speaking to the professor in charge. The confirmation mainly occurred the very same day as the emergency ( $60 \%$ of the whole sample), and was almost complete by the end of the following week (18 March). Almost half of the students who were at the university during the earthquake did not confirm their safety personally. Since in principle we make no distinction here between laboratories and the university as a whole, it is possible that this result is caused by how we framed the question. Yet, the dynamics of sheltering, examined in the following section, hint at some disarray as students moved back and forth between shelters and the university, a fact that resonates with this observation.

\subsubsection{Contact with Families}

Communication with their families was mainly done through cellphones $(66 \%)$, followed by smaller shares of public phones $(12 \%)$, e-mails $(12 \%)$, and other Internet services $(8 \%)$. This too was mostly achieved during the first day $(65 \%)$ and finished faster than the university, full confirmation with families being completed by 15 March. The survey was not specific about whether cellphones were used for phone calls, so some of those responses may include Short Message Service (SMS); the goal was to find whether the generalized difficulties using the cellphone network actually affected students. It is not surprising that nobody reported using landline telephones for safety confirmation purposes. Students also reported having received the official requests for safety confirmation from the university later during the following week.

When asked to identify the best (more efficient) way to confirm personal safety, students put a premium on e-mail $(23 \%)$ and cellphones $(22 \%)$. They also commented on other means of communication, such as public phones or other Internet services, without specifying which one was most useful. The number of respondents who did not answer or explicitly expressed not knowing the best alternative was as large as the two most popular options (22\%). The lack of response might derive from the difficulties experienced during those first days after the emergency, when no one means of safety confirmation was totally reliable.

\subsection{Taking Shelter in Sendai}

Questions about the second stage of the emergency sought to describe the behavior during the first few days in which students took shelter in the city. It does not include students who were outside Sendai during the earthquake.

\subsubsection{Reasons for Changing Shelter}

Most of the students took shelter starting Friday night, but still nearly 20 percent slept at their own homes, mainly because they saw no problem in doing so. There were only two cases in which problems at the shelters, many of which were crowded during the first days, were the cause of students moving back to their own homes. The large majority that slept in shelters did so at schools and other designated shelters, as can be seen in Figure 2. A third of those who went to shelters on the first night changed shelters at least once, mainly because they formed groups and stayed with friends or because they were looking for a more comfortable location and a stable supply of utilities and food. Some of the students reported a fire in one of the shelters close to the Sanjo dormitory, which obliged them to move somewhere else. Students stayed on average of two days in the first shelter ( $80 \%$ of students) and three to four days in the second shelter in Sendai (29\%).

Two characteristics of the sheltering behavior deserve mention. Those who initially decided not to take shelter but sleep at home are not the same students who finally decided to stay in Sendai. Thus, skipping the sheltering phase may have influenced the decision to leave the city. Besides, there is statistical association $(p=0.05)$ between the starting point (first bar, Figure 2) and the aftershock decision (last bar): a larger share of those in the university resolved to leave the

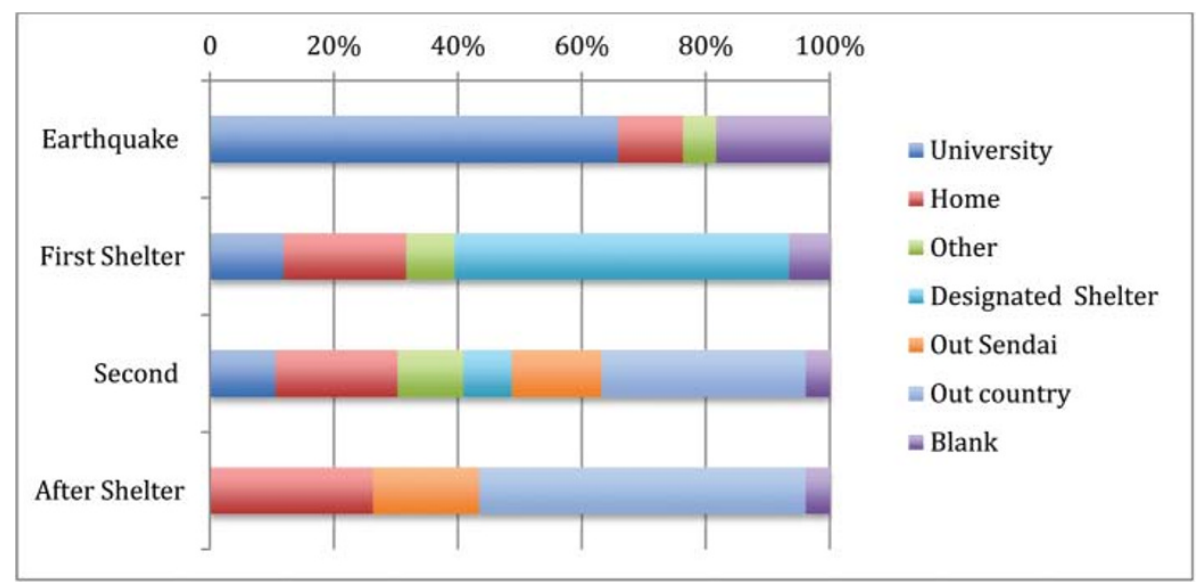

Figure 2. Changes of shelter during the initial part of the emergency (share of respondents) 
country, while the rest tried different strategies, specially postponing going out of the country in the initial phase of the emergency. This suggests that students who experienced the earthquake at the university perceived something there while leaving - for instance, that the situation was too bad (even if that was not the case) - and/or received some informationfor instance, that the university was going to close, that they better leave - that affected their subsequent decisions.

\subsubsection{Changes of Shelter during the Emergency}

From the summary in Figure 2, we can see that students had a very fluid reaction to the emergency, and moved frequently during the first days. Few of the students who were at the university during the disaster actually took shelter there. This was mainly because the university is not a designated shelter and the decision to organize one was taken after students were disbanded. Four students from the sample actually stayed in another university, Sendai Fukushi University (Figure 1), which is closer to the Sanjo dormitory and is also not a designated shelter. This suggests that most of the students actually went back home before deciding what to do and once there they had to find alternative places to take shelter.

We tested several variables and their association to the sheltering behavior. We found an association (significant at 0.01 ) between the decision about shelter site and the existence of a close relationship with a Japanese outside the university (33\% of the sample). In other words, it is more frequent for students with a close Japanese relationship to go home or somewhere else in Japan instead of leaving the country. There is also a weaker, still significant evidence of association between the sheltering decision and the time students had stayed in Japan: for those who had stayed less than a year and between two and three years it was more common to decide to leave the country than for the others. This suggests that both new comers and those finishing masters programs or having entered research status could also decide to leave more easily than those in the middle of their research.

\subsubsection{Reasons for Leaving Sendai}

Around half of the students staying in Sendai experienced difficulties in shelters, mainly because of lack of food and basic utilities. But these difficulties were not the main reason affecting post-disaster shelter decisions. Those who left Sendai indicated that their decision was motivated by the situation in the nuclear power plant, or other Fukushimarelated safety concerns. Students report coming to know about Fukushima almost immediately after events developed there, so they got information faster than the general population, which we suppose is related to their skills in IT. In contrast, evidence gathered through the interviews suggests that this observation can be a distortion on their memories about those days. Additionally, those who decided to stay in the city considered their homes to be safe and Sendai to be relatively back to normal.

\subsubsection{Relevance of Information Sources}

Students were asked about the sources of information that were most important for their decisions, whichever decision they made. The results, summarized in Figure 3, show the three most relevant sources were students' families, their laboratories, and people of their own nationality. The information source with overall larger positive valuation is people of the same nationality.

We did not include any questions about the content of this information in the questionnaire, but through semi-structured interviews it was possible to explore the issue. Families, once safety confirmation was possible, pressured students to return home. Problems at the nuclear power plant were the most frequently mentioned reason. Family pressure was not limited to parental concern, but extended family also directly and indirectly pressed students to return; their source of information was regularly foreign media and so students reported the problem of evaluating what was covered on television and what happened in Sendai. The role played by each student's laboratory varies from case to case. Some mention news from their labs as well as the university. In some cases students were encouraged to leave the city, in others students were visited by their professors who checked out their situation. Depending on the circumstances, some respondents could not meet their lab mates, while others stayed at their professor's home (Toushinroku, Takakura, and Kimura 2012). More importantly, students got together with friends, who were usually of their own nationality, stayed together, and made decisions together. The information entering these groups was different for each of them, but the preeminence of these three sources of information shows that students while looking for emotional support, and may end up not assessing the situation by themselves and relying upon the opinions of others. Local primary sources, which carried information specific to the situation and needs of the city, were left in the background, rather unimportant for most of the respondents.

Respondents indicate that their respective embassies played a limited role in their personal emergency decisions. This was the case even after embassies contacted 66 percent of those who stayed in Sendai, inquiring about their situation and/or encouraging them to evacuate the city. There is no statistical association between being contacted by the embassy and the decision made after leaving the shelter.

\subsection{Life in Sendai during the Aftermath}

The three quarters of the student population who remained in Sendai after the earthquake were asked about their experience of trying to reestablish normal life in the city. The main obstacle to remaining was utilities - gas, electricity and water-and, to a lesser extent, food and drinkable water supply. Only three people reported damage of their homes, although 18 considered the aftershocks a reason to stay outside of them. 


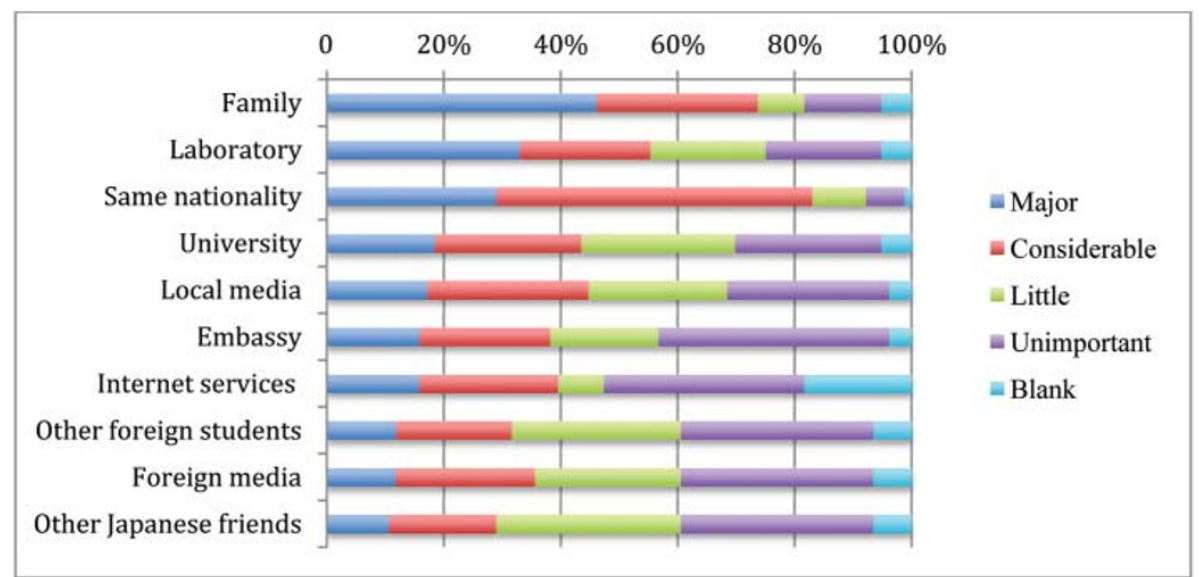

Figure 3. Relevance of information sources after the earthquake

Four-fifths of the students who answered this section reported having to queue in order to get food, water, or gasoline. The average waiting time was around 1.5 hours per line, and the total average time spent queuing was 4.5 hours. Respondents were free to explain the strategies they followed to get food; 60 percent of them actually bought it. Other alternatives included sharing with friends, using their own stocks, and receiving food from the shelter at which they stayed. From the students initially staying in Sendai, 67 percent encountered no problems moving around the city, mainly because of the common use of bicycles. Those who had problems were affected either by the shortage of gasoline or the disruption of public transportation.

\subsection{Sheltering Outside Sendai}

Figure 4 presents a summary of the movement of students out of Sendai, out of Japan, and eventually back again to the city. By Monday, 14 March, 45.3 percent of students had left Sendai, while the peak period of student departures from Japan was between 17 and 18 March. This number includes half of the students who in Figure 2 reported going home after the earthquake emergency. Because some of them decided later to move out of Sendai or Japan, less than 13 percent of international students in Sendai eventually stayed there the whole time. The main means of transportation were buses, presumably those going to Yamagata, from where some continued their trip by airplane, bus, or train. Some students mentioned also using buses provided by the embassies, as well as taxis or private cars.

The main destination was Tokyo, although replies included places ranging from Akita to Kobe. The average duration of the stay was of four nights, though this is the result of around 85 percent of the respondents staying a couple of days before moving on, and the other 15 percent taking shelter for between two and four weeks somewhere else in Japan before going back to Sendai. Although not in the proportion expressed while in Sendai, some students still experienced shortages of supplies in other cities, mainly of food and water. Anecdotal evidence suggests that this movement was far from easy for those who did not have a private means of transportation. Buses to Yamagata were crowded by locals trying to move out of Sendai. Yamagata, Niigata, and Narita airports were also overwhelmed, so some students had to spend at least one night at the airport before getting a seat on an outbound plane. Complaints of overpriced international air tickets were also mentioned. No student reported going to a third country to take shelter.

A final question in this questionnaire section inquired about the reentry permit required to come back to Japan and whether there were inconveniences leaving the country in a hurry. A couple of cases aside, most of the students had no problems in this respect.

\subsection{Back to Sendai}

Figure 4 presents the pace of students coming back until the Golden Week, equivalent to 90 percent of our sample.i The remaining 10 percent came back later during that month, and a couple of students returned in June and July. We asked students about the importance of a range of factors when setting the date of return (Figure 5). We grouped returning dates into six groups-"early comers," "second week of April," "third week of April," "late April," "Golden Week," and "late comers" - and tested how the date of return was associated with other variables.

For everyone discussions with his or her professor were the most important factor in deciding their return date. Students returning early did so after talking to friends and family, so for them the restart of classes was less important. There is a weak ( $p=0.0658)$ association that merits comment: the later students came back, the more importance they gave to the media. This suggests that although students seem not to have placed as much importance to the news as they gave to other factors, media information certainly influenced their behavior. Figure 5 shows that in addition to discussion with 


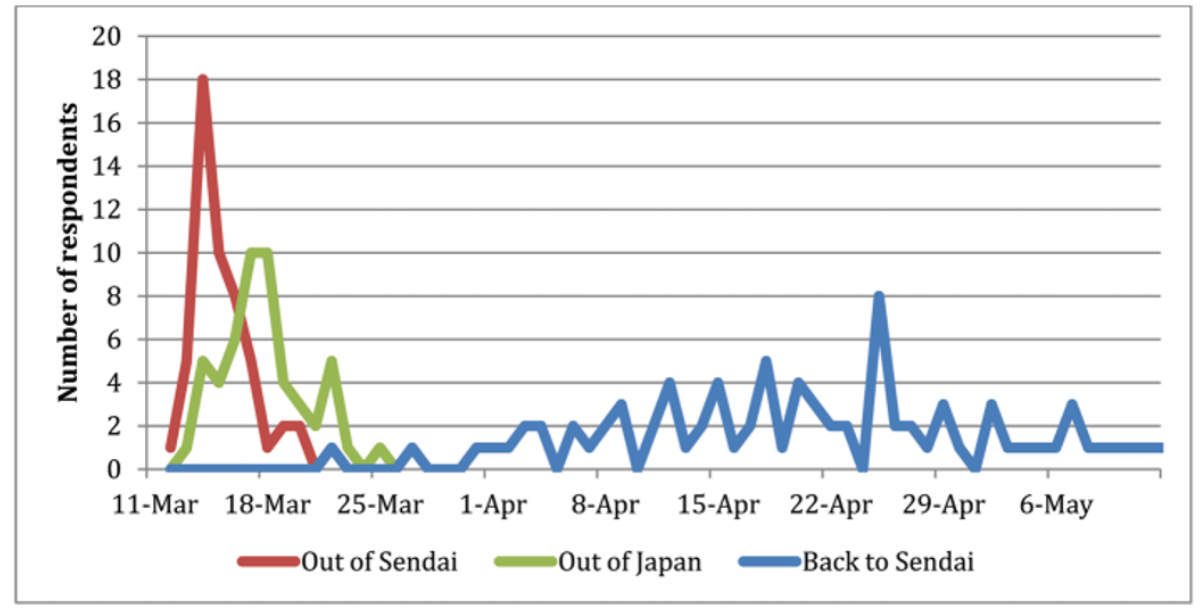

Figure 4. Movement of students from and to Sendai

professors other relevant factors were important too. News from non-Japanese friends in Sendai became the second most important factor in setting return dates, with positive appraisal equal to that of the restart of classes. Warnings from the government, which mostly went unchanged during the months following the triple disaster, appear at the bottom of the importance ranking. Similar to what happened right after the emergency's outbreak, foreign governments seem to have played only a secondary role during the whole incident. In contrast, those international students with close Japanese acquaintances actually gave more importance to the news from Japanese friends than the rest of the students.

\subsection{In Hindsight}

The last section of the questionnaire included four questions about the overall experience of the international students during the emergency. Three of them were open questions and, thus, the qualification of the answers was done manually.

\subsubsection{Evaluation of the Response}

Questioned about their overall experience, the students in the sample had a mostly positive view of the university's reaction $(54 \%)$. Respondents recognized the magnitude of the challenge, and thus praised Tohoku University for being good enough in its response to the disaster. Only 6 percent of the respondents were openly negative, while 40 percent opted for a neutral stance or no response at all. The few negative aspects mentioned included slowness, both in terms of information provision and decision making.

A minority of students (17\%) were willing to criticize their own reaction, but the most common answers were neutral stances or no comments (55\%). Although the negative appraisals include conceding to panic and the emotion of the

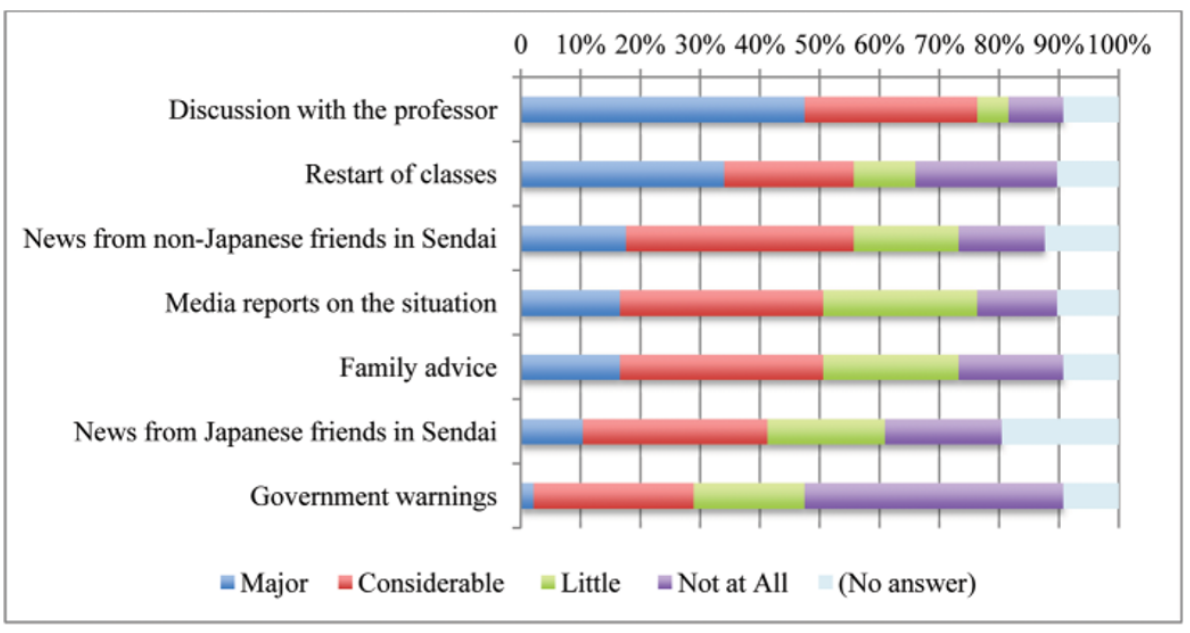

Figure 5. Factors influencing the return date 
moment, neutral replies present a deterministic view. Several students stated they mainly limited themselves to following orders; in their own words "[I] did what I had to do." It is not clear whether this posture implies that students felt they never had the option to decide what to do next. This seems consistent with a common attitude observed throughout the survey, our interviews, and other documents (Toushinroku, Takakura, and Kimura 2012), which was the student tendency to give preeminence to secondary sources of information.

\subsubsection{Safety Confirmation Tools and Emergency Drills}

Of special relevance for the analysis, there was general approval of safety confirmation and the evacuation training provided by the university. But during the subsequent stages of the emergency, the role of the university is less clear. A large share of the students $(71 \%)$ had received earthquake training, and nearly 58 percent actually put that knowledge into practice. Regardless of whether students did or did not apply what was learnt through the drills, the training did influence sheltering behavior. Trained students were more likely to go to designated shelters (significant at 0.01 ), as well as more likely to decide to leave the country. Whether leaving the country is actually an unintended consequence of drills and other trainings, since they promote following fixed protocols, is an issue that deserves being explored in future studies.

When asked about the best possible reaction to a future emergency, the main concern was information provision. Among the characteristics students expect from this information are swiftness, accessibility in terms of language, and reliability. Students also conceded some usefulness to drills, keeping an emergency stock of food and water at home, and cooperating with friends, while concerns over safety confirmation are barely mentioned.

\section{Discussion: Strengths and Weaknesses during the Emergency Response}

The survey presents a portrait of the experience of international students after the triple disaster, describing their initial reaction, the stresses to which they were exposed, and the decisions that followed and the reasons behind them. It covered the period from the outbreak of the emergency until students returned to Sendai. From the collected findings, there are two major issues that deserve attention: the actual performance of the existing disaster preparations and the complications of information collection and provision.

\subsection{Performance of the Existing Disaster Preparations}

For everyone in the Tohoku area, the 11 March earthquake was the strongest tremor they had ever felt and it is no surprise to find a very turbulent situation right after the quake in which students moved around, back and forth between different shelters, homes, and the university. But students followed what they had learned from yearly drills and evacuation procedures were fulfilled. Those preparations were successful, including the safety confirmation process. Full confirmation with their families took four days and one week with the university. However, reports from the school and university do not coincide with students' replies: besides the initial paper-based confirmation, the Engineering School undertook complementary safety confirmation through the Internet, which finished by 30 March, and the university also undertook a centralized effort that only received less than thousand replies. While redundancy was favored by the university to guarantee that the safety confirmation process covered everyone, students may have considered that replying once was good enough. The problem after 18 March was to harmonize the overlap of information, which took lots of time and effort to verify (Nakajima 2011). Concern for efficiency suggests developing an unified safety confirmation systems. But professors from the School of Engineering favor a multiplicity of confirmation means, since the top priority is connecting with 100 percent of the students. Despite criticisms in the mass media, cellphone and Internet infrastructures were good enough to satisfy the basic goal of keeping relatives in touch with the students. Even though students did not conclusively cite any single method as the best means, an improved safety confirmation method is not a priority concern.

The major issue on this occasion was something not covered by the drills: the period of time that followed the main tremors before student safety confirmation occurred. Students exhibited erratic sheltering behavior, changing places during the first post-tremor days as they went back to the school or joined friends. In this respect, research by the Sendai International Relations Association (SIRA) found that this behavior could have a negative impact during emergencies (Sendai City Government 2013). The original idea of shelters is to offer a safe haven for the inhabitants of the area around the shelter. When students formed groups and moved to shelters far from their residences, Japanese staying in those shelters may have felt uneasy. There is anecdotal evidence of this uneasiness occurring in two shelters, though it did not become a major problem. A possible lesson is to maintain temporary shelters inside the university premisessomething that Tohoku University is already undertaking. Students are not necessarily familiar with the location and the implications of sleeping in a shelter, and part of recovering their sense of security is meeting with their friends. So staying at the university is an attractive option to maintain calm. Future drills should include a broader picture of what it is like to experience a megadisaster in a densely populated country by including in the training program anticipated conditions and coping strategies for several days after the occurrence of the earthquake - hopefully one week (Gomez 2013). In this way, students and laboratories can be more autonomous in their responses to the emergency. SIRA and international students from Tohoku University have already held such a drill for the first time. 
The survey alone does not offer enough information to evaluate the impact of advising students to go home (sometimes to the other side of the world), but some inputs can help informing the discussion. Between the peak of students leaving Sendai and those leaving the country (Monday 14 and Friday 18, respectively) the situation of at least one of the engineering campuses was practically recovered. The report of radiation on-campus never indicated spikes to dangerous levels. Interviews revealed that students were exposed to multiple stresses on their way home: long lines and prolonged waits to gain access to transportation, sleeping in airports, paying very high prices for air tickets, and experiencing a mood of increased anxiety generated by the stress encountered everywhere around them. This could possibly be the source of additional PTSD exhibited by some students. There is also evidence showing that students leaving can trigger panic flight behavior among other foreign national communities (Gomez 2012). International students not only study, but they also are part of the population of the city, which can affect the distribution of food and other economic activities.

Despite these issues, the majority of students left before the university countermeasures team had made any decision, so both reforms to the slow, centralized response and a strengthening of the link between international students and the university are warranted. The survey showed that a close relationship to a Japanese citizen was associated with a more balanced reaction to the emergency, but the number of students having such a relationship is limited, despite established efforts to generate such bonds, for example, through homestays, holiday tours, and tutors. Two future tasks emerge from this situation: discovery of the reasons why international student contact with Japanese culture and society is not bigger and exploration of the possibility that by deciding to close the university broke the linkage of students and local society, making their reaction closer to that of tourists. Part of this connection is emotional, a sphere of human interaction that goes beyond the present article's methodology, and other part is informational, which is the next point at stake.

\subsection{Information Collection and Provision}

The survey shows that students relied more heavily for information, advice, and support on the family, the laboratory, and friends of the same nationality during the emergency: in other words, they depended on secondary sources of information. The grouping behavior in shelters is consistent with this finding. Yet according to the questions on safety confirmation, students actually had access to the Internet for information. These factors hint at passivity in student information demand. Fear of radiation from Fukushima is a good example. International hype reached the families of students abroad, and families pressured students to evacuate without actual knowledge about the situation in Sendai. Through the interviews, many recognized that the city was quickly regaining normality, yet pressure coming from their homes abroad was stronger.
Institutions such as Tohoku University were capable of making scientific assessments of the situation and providing expert advice, which the university eventually did, but it was too late to inform international students. One week after the emergency, a research center of the university was already monitoring and posting on the Internet radiation measurements that showed the limited magnitude of the threat, but this source of information was not mentioned by any respondent of the survey - although it was possible to confirm that some knew about it through the interviews. Given the passivity of students, publishing information on a web page might not be enough.

As students returned, professors as representatives of the university became more relevant, as well as other international students already in Sendai. At that point Facebook groups and e-mail magazines emerged, directly posting information about the recovery process in the city. The importance assigned by students to this source of information seems to resonate with the Tohoku University strategy of asking international students themselves to tell prospective students about the positive evolution of the region in general and Sendai in particular. The major challenge for the university, as pointed out by the survey, is serving as a timely source of information. Even if the university is not the primary source of decisionmaking information, it has the ability to work as a conduit for information, using strategies similar to the automatic service of safety confirmation in order to let students know about the situation of the city in a more timely fashion and from more reliable sources.

There are several factors that complicate the task of satisfying the wish of international students for reliable information. It has to be clear from the outset that students are the only ones who can decide what they should do next. Otherwise, expecting to be told what to do instead of what the situation is can affect the willingness to help of other actors in the capacity of providing or channelizing information because it could imply being held responsible for whatever they say. Information during disasters is always full of uncertainty, so officials responsible for providing information are naturally hesitant about making mistakes; that the persons demanding information expect to be told what to do makes this hesitancy worse. This attitude could dissuade capable emergency information providers, such as the university, from actively disseminating information before it is absolutely sure that information is accurate.

The sources of information that were relevant for students were not necessarily the ones that could be expected to possess the better assessment of the situation in Sendai. Families mostly relied on foreign media, which can be poorly informed or biased, as students recognize themselves. There is no evidence that friends of their own nationality have better information than students themselves have. If everyone relied on somebody else in our sample to assess the available data, then who was assessing the situation? Local media were not among the most important sources of information. Embassies 
also generated little information themselves. Some of them did offer the means to move out of Sendai, but in many cases they did not have knowledge of the city, did not have the capabilities to do what they intended to do, also suffered from a language barrier, lacked prepared concrete emergency plans, and in some cases created conflicts among compatriots (Gomez 2012).

Given this situation, it seems that universities are in a privileged position to filter information and reach students who need local, trustable information in order to evaluate what to do next. University laboratories are among the top sources of information contacted by students and most probably have a deeper knowledge of the area than families and friends abroad, which can make the difference under post-disaster stress. Evidence from the Toushinroku, Takakura, and Kimura (2012) and other interviews show that several professors directing laboratories undertook this kind of intervention strategy. They took students to their homes, offered shelter, food, and tranquility after the disaster. They even helped international students to gain access to different information sources. But they stopped short from telling students what to do, even when they were asked for direction. What professors offered was some security and access to reliable information. But students remained responsible for themselves. This may not be a strategy that could be generalized, but it can be the start for future considerations on the role of professors and the university during emergencies.

\section{The Challenge of Informed Autonomous Decision-Making}

The present article offers a general picture of the reaction of international students to a mega-disaster in a globalized urban setting. There is little research about this population in the literature and thus the research is centered on describing the particular case at Tohoku University's School of Engineering, trying to identify sources of vulnerability and disaster management lessons. Possible lessons from the survey include widening the time range of action included on disaster drills, and considering the possibility of universities becoming a "designated" shelter for international students wishing to stay on campus. Safety confirmation does not appear to be a problem for students, although universities may have to find ways to harmonize different sources of information more efficiently.

Some factors that can support the distinct vulnerability of international students were identified. Students often appeared to be passive information receivers and to rely mostly on secondary, presumably decontextualized, sources of information in order to decide what to do after the disaster. Accelerated reaction could expose them to additional harm and be economically onerous. Emphasis was given to the potential role of the host university as an authoritative information provider, recognizing that it is desirable to have multiple providers of advice during emergencies. Even if every lesson is reflected in new strategies, disaster may strike when students are not at the university, or some students would still prefer to leave the campus without confirming safety and go home. It would be equally wrong to expect students just to do nothing while a centralized emergency response team is formed and decisions are made. In those cases, other social actors start playing a significant role during an emergency. Actually, international students are not different from other Japanese citizens. The 2009 White Book on Disaster Prevention prepared by the Cabinet Office includes a survey on what is actually the most useful thing during a disaster. This shows that impacted individuals also give the highest priority to family, themselves, and neighbors, followed by other organizations (Cabinet Office 2009). But for international students, such networks are not always rooted in the area, or the linkage is not as strong: just a couple of respondents mentioned being helped by their landlady/ landlord, and 64 percent reported having no close relation to any Japanese. The results from our survey suggest that deeper links with Japanese society influences behavior after a disaster and can positively influence future reaction during the extended phase of a similar emergency. In theory, helping students to integrate more with Japanese society might also improve their decision-making during a crisis situation. But there is no silver bullet to advance this objective, a longstanding problem. In the meantime, universities are the strongest link between students, the city, and the region, and so they should take the lead in addressing future challenges.

\section{Acknowledgments}

The first part of the research was undertaken while I was a Collaborator for Research and Education at the Graduate School of Environmental Studies, Tohoku University, and its conclusion was made possible by the support of the Japan Society for the Promotion of Science (JSPS) Kakenhi Grant Number 34310 . The research would not have been possible without the support of the School of Engineering and Professor Mikiko Nakajima, Division of International Education and Exchange, who welcomed the idea, took part in the research design and offered precious comments during the analysis. I am very thankful to them and to all the persons who helped during the research and publication. Any mistakes or inaccuracies are the sole responsibility of the author.

\section{Notes}

Disabilities were also included in that occasion. The information is available at: http://www.law.cornell.edu/uscode/text/42/5151.

ii The Golden Week is a Japanese term for the period containing the public holidays in April 29 and May 3, 4, and 5. 


\section{References}

Agresti, A., and B. Finlay. 2009. Statistical Methods for the Social Sciences. 4th Edition. Upper Saddle River, NJ: Pearson Education / Prentice Hall International.

Asahi Shinbun. 2011. Thoughts after 10 Days of the Disaster (震災10日 目の思(). Asahi Shinbun, 20 March 2011. http://www.cnposts.com/ Original/7094.aspx (in Japanese).

Bankoff, G. 2012. Historical Concepts of Disaster and Risk. In: The Routledge Handbook of Hazards and Distaster Risk Reduction, edited by B. Wisner, JC Gaillard, and I. Kelman, 37-47. Oxon: Routledge.

Cabinet Office. 2009. White Book on Disaster Prevention (防災白書). Tokyo: Cabinet Office of Japan (in Japanese).

Cavanaugh, J. C. 2006. Effectively Managing Major Disasters. The Psychologist-Manager Journal 9 (1): 3-11.

Deebaj, R., M. Castrén, and G. Öhlén. 2011. Asia Tsunami Disaster 2004: Experience at Three International Airports. Prehospital and Disaster Medicine 26 (01): 71-78.

Drabek, T. E. 1999. Understanding Disaster Warning Responses. The Social Science Journal 36 (3): 515-523.

Elder, K., S. Xirasagar, N. Miller, S. A. Bowen, S. Glover, and C. Piper. 2007. African Americans' Decisions not to Evacuate New Orleans before Hurricane Katrina: A Qualitative Study. American Journal of Public Health 97 (Supplement 1): S124-S129.

Gomez, O. A. 2012. Human Security and the Limits of Nation-States' Responsibility: The Case of "Foreigners" in Sendai during 2011 Great East Japan Earthquake. In: Proceedings of the Second Istanbul Human Security Conference, organized by Coventry University, Kadir Has University, Middle East Technical University, and Abant Izzet Baysal University, Istanbul, 18-19 October 2012, 269-285.

Gomez, O. A. 2013. The Emergence of Food Panic: Evidence from the Great East Japan Earthquake. Journal of Disaster Research 8 (7): 814-825.

Henry, M., A. Kawasaki, and K. Meguro. 2012. Foreigners' Disaster Information Gathering Behavior after the 2011 Tohoku Earthquake (Part 3) Analysis of Foreign Students Considering Their PostDisaster Action (特集 持続可能な都市システムの構築をめざし 乙 (ICUS)). Seisan Kenkyu 64 (4): 497-503 (in Japanese).

Hyogo Earthquake Memorial 21st Century Research Institute, ed. 2011. Handbook of Disaster Management. Kobe: Hyogo Earthquake Memorial 21st Century Research Institute.

IASC (Inter-Agency Standing Committee). 2006. Protecting Persons Affected by Natural Disasters: IASC Operational Guidelines on Human Rights and Natural Disasters. Washington, DC: BrookingsBern Project on Internal Displacement.

Kimura, R. 2012. Do Non-Japanese Become Vulnerable in a Disaster?! SISTAR Japan Newsletter (Society for Intercultural Education Training and Research) Spring 2012: 15-17.

Kõlves, K., K. E. Kõlves, and D. De Leo. 2013. Natural Disasters and Suicidal Behaviours: A Systematic Literature Review. Journal of Affective Disorders 146 (1): 1-14.
Kuban, R., and H. MacKenzie-Carey. 2001. Community-Wide Vulnerability and Capacity Assessment (CVCA). Ottawa: Office of Critical Infrastructure Protection and Emergency Preparedness, Canada.

Matsubayashi, T., Y. Sawada, and M. Ueda. 2013. Natural Disasters and Suicide: Evidence from Japan. Social Science \& Medicine 82 (C): 126-133.

Naito, M. 2011. Health Management of Vulnerable Populations. In: Emergency Response. Vol. 2, 256-259. Hyogo Earthquake Memorial 21st Century Research Institute.

Nakajima, M. 2011. Safety Confirmation of International Students Following the Great East Japan Earthquake - Cases of the School of Engineering and the Student Exchange Division, Tohoku University. Journal of International Student Advisors and Educators 14: 7-11.

Omura, M. 2012. After an Unprecedented Large Disaster, What Happened with the Scattered Foreigners? In: East Japan Big Earthquake and Foreign Immigrants, edited by E. Suzuki, 34-55. Tokyo: Akashi Books.

Reisinger, Y., and J. C. Crotts. 2010. Applying Hofstede's National Culture Measures in Tourism Research: Illuminating Issues of Divergence and Convergence. Journal of Travel Research 49 (2): $153-164$.

Schuh, J. H., and F. Santos Laanan. 2006. Forced Transitions: The Impact of Natural Disasters and Other Events on College Students. New Directions for Student Services 2006 (114): 93-102.

Seabra, C., S. Dolnicar, J. L. Abrantes, and E. Kastenholz. 2013. Heterogeneity in Risk and Safety Perceptions of International Tourists. Tourism Management 36: 502-510.

Sendai City Government. 2013. Great East Japan Earthquake Disaster: Sendai City Disaster Record-First Year Record of Activities (東日本 大震災: 仙台市震災記録誌〜発災加 1 年間の活動記録〜). Sendai: Sendai City Government (in Japanese).

Sphere Project. 2011. Humanitarian Charter and Minimum Standards in Disaster Response. Rugby, UK: Practical Action Publishing.

Steckley, M., and B. Doberstein. 2011. Tsunami Survivors' Perspectives on Vulnerability and Vulnerability Reduction: Evidence from Koh Phi Phi Don and Khao Lak, Thailand. Disasters 35 (3): 465-487.

Suzuki, M., ed. 1996. International Students at That Time. Tokyo: Kawashima Shoten.

Tompkins, E. L., L.-A. Hurlston, and W. Poortinga. 2009. Foreignness as a Constraint on Learning: The Impact of Migrants on Disaster Resilience in Small Islands. Environmental Hazards 8 (4): 263-277.

Toushinroku, H. Takakura, and T. Kimura. 2012. Oral Narrative of the Disaster Experience: The 3.11 Told By 90 Persons from Tohoku University (Kikikaki shinsai taiken: Tohoku Daigaku 90 jin ga kataru 3.11). Shinsensha, Tokyo.

Weiss, R. S. 1994. Learning from Strangers: The Art and Method of Qualitative Interview Studies. New York: Free Press.

Wisner, B., JC Gaillard, and I. Kelman. 2012. The Routledge Handbook of Hazards and Distaster Risk Reduction. Oxon: Routledge.

Yonekura, R. 2012. Media Use and Information Behaviour of Foreigners in Japan during Disaster (災害時における在日外国人のメディア 利用と情報行動: 4 国籍の外国人を対象とした電話アンケート の結果から). The NHK Monthly Report on Broadcast Research 62 (8): $62-75$ (in Japanese).

Open Access This article is distributed under the terms of the Creative Commons Attribution License which permits any use, distribution, and reproduction in any medium, provided the original author(s) and source are credited. 